\title{
Community Awareness on Neglected Tropical Diseases \& Compliance to Mass Drug Administration against Lymphatic Filariasis in Bardiya and Banke Nepal
}

\author{
Mangal Bahadur Tharu' ${ }^{* 1}$, Surya Kumar Magar ${ }^{1}$, Rajendra Bahadur Sunar ${ }^{1}$ \\ ${ }^{1}$ International Nepal Fellowship-Nepal \\ mtharu2004@yahoo.com \\ hospital.manager@surkhet.nepal.inf.org
}

Abstract

Setting: Nepal is a country with high prevalence of Leprosy and Lymphatic Filariasis(LF) mostly at Terai (plain) districts. The coverage of annual campaign of mass drug administration (MDA) for the prevention of Lymphatic Filariasis is low. Nepal is committed to achieve the goal set by WHO achieving elimination of Lymphatic Filariasis by year 2020 and the country applies MDA strategy and conducts yearly campaign of Mass Drug Administration.

Objectives: To determine community awareness on NTD especially Lymphatic Filariasis,mode of transmission of it, measures of prevention and compliance of MDA recently conducted in 2016 in Nepal and reasons for not complaining it.

Design: A descriptive study of people's awareness on NTD (Lymphatic Filariasis) and compliance to MDA campaign 2016 in Nepal.

Results: Out of 139 respondents only n=84 (60\%) know Lymphatic Filariasis can transmit from mosquito bite. Protect from mosquito bite is preventive measure of LF was said by $24 \%$ and to take drugs (MDA) was said by $40 \%$. Knowledge of other NTD (Kala-azar, Dengue and Trachoma) was found even less. Compliance to MDA 2016 was found $71 \%$ in total where as $77 \%$ in rural population and $58 \%$ in urban population.

Conclusion: Peoples' knowledge is low in the area of neglected tropical diseases such as Lymphatic Filariasis which might be one of the reasons of poor compliance to MDA annual campaign. Urgent action need to be taken toreach the goal of elimination of Lymphatic Filariasis from Nepal by year 2020.

Keywords: NTD, Lymphatic Filariasis, Mass Drug Administration Compliance, Nepal, International Nepal Fellowship

\section{BACKGROUND}

Nepal is a land locked country situated between two big countries China in the north and India at other 3 directions. The country is reach in diversity with different geographical regions; plain at southern part with covering area $17 \%$ and hills and mountains at northern part. The hilly area covers $65 \%$ of total area of Nepal and $45 \%$ of population inhibits on it and mountainous part covers $16 \%$ area with only $8 \%$ population.(Geography of Nepal) Nepal has 75 districts and the total population of it is $26,494,504$. Nepal is under developed country and majority population liveat rural areas. The health care services are mainly provided from periphery level health care institutions health posts and health centers in rural areas. Hospitals are mainly situated at district headquarters and specialist hospitals are at major cities.

Although the Neglected Tropical Disease (NTD) covers a wide variety of diseases, in Nepal there are only certain types of NTD such as Leprosy, Lymphatic Filarasis, Kala-azar, Dengue and Trachoma. Leprosy has been 
Community Awareness on Neglected Tropical Diseases \& Compliance to Mass Drug Administration against Lymphatic Filariasis in Bardiya and Banke Nepal

eliminated in national level whereas 15 districts are still withhigh prevalence rate $>1 / 10,000$ population.The number of high prevalent districts is fluctuating every succeeding year. Lymphatic Filariasis is still a public health problem in Nepal. The prevalence is high at districts of Terai (plain) belt. Kala-azar is public health problem ineastern and central Terai region; mainly in eleven districts. The national incidence of Kala-azar is $0.34 / 10000$ population. Of the total reported 785 cases of Dengue, only 6 were from western part of Nepal. (Government of Nepal, 2070-2071 (2013-2014)). Trachoma is leading infectious cause of blindness in Nepal and in world. It was a public health problem in recent past years in Nepal and 19 districts were endemic with Trachoma. With use of SAFE (Surgery, Antibiotic, Face Washing, Environmental improvement) interventions in endemic districts, the National Trachoma Program (NTP) has been able to eliminate trachoma from 18 (Kailali, Kanchanpur, Chitwan, Nawalparai, Surkhet, Banke, Bardiya, Dang, Kapilbastu, Bara, Parsa, Doti, Rolpa, Dailekh, Sarlahi, Rukum, Rautahat and Rasuwa) endemic districts of Nepal. (SANGH, 2014).

Nepal government has been continuously implementing MDA (Mass Drug Administration) program each year for the prevention of Lymphatic Filariasis. The coverage of population at risk with MDA has been seen less than expected. Banke district is one of the high prevalent Filarial district of Nepal and in $6^{\text {th }}$ round MDA program conducted in year $2072(2016)$ the coverage is only $62 \%$. In Bardiya, the coverage of $4^{\text {th }}$ round MDA program 2071 (2015) at Bardiya was 82.82\%. In Kailali, the coverage was 66\% in MDA round $2^{\text {nd }}$ program 2070 (2014). Despite continuous efforts the coverage of MDA program is not satisfactory and varies in years and in districts. This situation demands an independent study to know the actual situation and reason for less compliance of MDA.

Our visits to district public health offices of Bardiya, Kailali and Banke districts and information gathered through discussions with key personals also supported above situation of prevailing public health problem of Lymphatic Filariasis high in the area and triggered us to conduct independent sample survey on NTD focusing more on Lymphatic Filariasis.

\section{METHODS}

\section{Study Design}

This is a descriptive retrospective study of people's awareness and compliance to MDA(Mass Drug Administration) campaign 2016 in Nepal for prevention of Lymphatic Filariasis.

\section{Setting}

Nepal is a country of high prevalence of Lymphatic Filariasis. The prevalence of Lymphatic Filariasis is higher in plain region (Terai belt). The World Health Assembly has passed a resolution in 1997 calling for "the elimination of Lymphatic Filariasis as public health problem". The elimination is defined as the Microfilaraemia rate is less than $1 \%$ in all area of endemic countries. This involves all endemic countries using MDA (Mass Drug Administration) as core strategy.(World Health Organization, 2010). Nepal is committed to achieve the WHO regional goal of eliminating Lymphatic Filariasis as public health problem (micro filarial rate $<1 \%$ ) by the year 2020. The country is organizing MDA program every year at endemic districts and have completed several rounds. The recommended regimen for MDA program is $6 \mathrm{mg} / \mathrm{kg}$ of body weight diethylcarbamazine citrate (DEC) + 400 mg albendazole once in a year with 6 rounds.(MOHP, 2072)The MDA program for the year 2072073 (2016) has recently been completed in endemic districts of Nepal.

\section{Study Population}

The Adult general population from Magaragadi VDC Bardiya (60 respondents from rural Tharu community), KhajuraKhurda VDC Banke (25 respondents from rural Madhesi community), NepalgunjSub-metropolitan city Banke(25 respondents of urban area) and INF Banke Clinic Nepalgunj clients visiting from any community (27 respondents) were selected. 
Community Awareness on Neglected Tropical Diseases \& Compliance to Mass Drug Administration against Lymphatic Filariasis in Bardiya and Banke Nepal

\section{Data Variables, Sources of Data and Data Collection}

The data variables are number of respondents known to NTDs, preventive measures of different NTDs, mode of transmission of Lymphatic Filariasis, compliance of last MDA campaign held in 2016, reasons for not compliance and ideas of respondents for improvement of program compliance. The source of data is interview records.

A data collection format was designed and tested prior to going for data collection at the field and necessary revision was made. Enumerators were selected from different backgrounds, 3 from FCHVs (Female Community Health Volunteers), 2 from church youths and INF's clinic staffs.

In community, respondents were selected randomly and one from each household. Purposefully male and female respondents were selected one after another alternatively. Although planned 150, a total of 143 respondents were interviewed from three different sectors(rural, urban and mixed groups). Among the interviewed, 4 were Non-Nepali respondents and were excluded from total. And hence only 139 records were reviewed ultimately.

\section{Analysis and Statistics}

Data were entered at Microsoft Excel spread sheet and were analyzed with use of simple Microsoft Excel formulas.

\section{Ethics Approval}

Prior to interview, respondents were informed about the enumerator and his/her affiliation being with INF and the purpose of data collection. Informed verbal consent was obtained from each respondent.

\section{RESULTS}

Of the total 139 respondents, nearly 90\% respondents have heard about Lymphatic Filariasis whereas other NTDs, Kala-azar 28\%, Dengue 25\% and Trachoma 32\% (Table No. 1). Commonest problem at society was said Lymphatic Filariasis by $31 \%$ respondents. Knowledge of preventive measures in listed NTDs was found poor. Only $16 \%$ respondents said the preventive measure of Kala-azar is to protect from mosquito bite and $6 \%$ said cleanliness of environment. Preventive measures of Dengue was said as protection from mosquito bite by $9 \%$ and cleanliness of environment by $6 \%$ and destroy stagnant water by $2 \%$ only as shown at table no 5 . Although not very good but compared to the above mentioned other NTDs, peoples' awareness level is slightly better in Lymphatic Filariasis. 60\% respondents said the mode of transmission of Lymphatic Filariasis is mosquito bite and preventive measures of it is to take medicine (distributed at MDA) was said by $40 \%$, similarly protection from mosquito bite was said by $24 \%$, cleanliness of environment was said by $14 \%$ (Table No 4). Preventive measure of Trachoma, face washing was said by 7\%, taking medicine (MDA) said by 3\% and environment cleanliness said by $4 \%$ only. Regarding source of information majority said they got information from health worker $33 \%$, whereas from radio $12 \%$.

Table1. Heard about Neglected Tropical Diseases (Kala-azar, Lymphatic Filariasis,Dengue, Trachoma), Magaragadi VDC Bardiya, Kajurakhurda VDC and NepalgunjSub-metropolitan CityBanke, 2072/2073

\begin{tabular}{|l|l|c|c|}
\hline SN & Neglected Tropical Diseases & Number & Percentage \\
\hline 1 & Kala-azar & 39 & $28 \%$ \\
\hline 2 & Lymphatic Filariasis & 124 & $89 \%$ \\
\hline 3 & Dengue & 35 & $25 \%$ \\
\hline 4 & Trachoma & 45 & $32 \%$ \\
\hline
\end{tabular}

American Research Journal of Public Health

Page 45 
Community Awareness on Neglected Tropical Diseases \& Compliance to Mass Drug Administration against Lymphatic Filariasis in Bardiya and Banke Nepal

Table2. Disease most common at community: Respondents' view, Magaragadi VDCBardiya, Kajurakhurda VDCand NepalgunjSub-metropolitan CityBanke, 2072/2073

\begin{tabular}{|l|l|c|c|}
\hline SN & Neglected Tropical Diseases & Number & Percentage \\
\hline 1 & Kala-azar & 9 & $6 \%$ \\
\hline 2 & Lymphatic Filariasis & 43 & $31 \%$ \\
\hline 3 & Dengue & 13 & $9 \%$ \\
\hline 4 & Trachoma & 8 & $6 \%$ \\
\hline
\end{tabular}

Table3. Measures of prevention of Kala-azar: respondents' knowledge/view Magaragadi VDC Bardiya, Kajurakhurda VDC and Nepalgunj Sub-metropolitan CityBanke, 2072/2073

\begin{tabular}{|l|l|c|c|}
\hline SN & Preventive measures & Number & Percentage \\
\hline 1 & Protect from mosquito bite & 23 & $16 \%$ \\
\hline 2 & Cleanliness of environment and personal hyegine & 8 & $6 \%$ \\
\hline 3 & Take medicine & 5 & $3 \%$ \\
\hline 4 & Eat fresh food/clean water & 3 & $2 \%$ \\
\hline 5 & Other (control Kala-azar, Kill Kala-azar) & 2 & $1 \%$ \\
\hline
\end{tabular}

Table4. Measures of prevention of Lymphatic Filariasis: respondents' knowledge/view,Magaragadi VDC Bardiya, Kajurakhurda VDC and NepalgunjSub-metropolitan CityBanke, 2072/2073

\begin{tabular}{|l|l|c|c|}
\hline SN & Preventive measures & Number & Percentage \\
\hline 1 & Protect from mosquito bite & 34 & $24 \%$ \\
\hline 2 & Cleanliness of environment and personal hygiene & 20 & $14 \%$ \\
\hline 3 & Take medicine & 56 & $40 \%$ \\
\hline 4 & $\begin{array}{l}\text { Stop mosquito growth (Do not let water stagnant, } \\
\text { use pesticide, destroy mosquito and insects) }\end{array}$ & 4 & $3 \%$ \\
\hline 5 & Awareness raising & 2 & $1 \%$ \\
\hline 6 & Eat fresh food & 5 & $4 \%$ \\
\hline 7 & Hot compress with cactus fluid & 1 & $1 \%$ \\
\hline 8 & God will save no need to take medicine & 1 & $1 \%$ \\
\hline
\end{tabular}

Table5. Measures of prevention of Dengue: respondents' knowledge/view, Magaragadi VDC Bardiya, Kajurakhurda VDC and Nepalgunj Sub-metropolitan City Banke, 2072/2073

\begin{tabular}{|l|l|c|c|}
\hline SN & Preventive measures & Number & Percentage \\
\hline 1 & Protect from mosquito bite & 12 & $9 \%$ \\
\hline 2 & Cleanliness of environment and personal hygiene & 8 & $6 \%$ \\
\hline 3 & Take medicine & 5 & $4 \%$ \\
\hline 4 & Stop mosquito growth (Do not let water stagnant) & 3 & $2 \%$ \\
\hline 5 & Eat fresh food & 1 & $1 \%$ \\
\hline
\end{tabular}

About recently conducted MDA campaign for the Lymphatic Filariasis prevention, 96\% said that they know the program was conducted however only 58\% respondents said they took medicine distributed at that annual campaign. While looking to the total family members of the respondents $(n=830)$ only(n=587) $71 \%$ took medicine at the MDA campaign. Major reasons for not taking medicine at MDA campaign was said suffering from other illness by $44 \%$, fear of drug side effect $24 \%$ and being out of area at the time of campaign $22 \%$. 
Community Awareness on Neglected Tropical Diseases \& Compliance to Mass Drug Administration against Lymphatic Filariasis in Bardiya and Banke Nepal

Comparison of MDA compliance at rural and urban population,we found people residing at rural area has better compliance to MDA than people at urban setting.During the last MDA 2016, 77\% of people residing at Magaragadi VDC (rural) took medicine during the MDA campaign, similarly 77\% people of Khajurakhurda VDC (rural) and 58\% of people residing at Nepalgunj Sub-metropolitan city (urban) took MDA medicine during the campaign. The OR ratio is $>1$ in rural settingand $<1$ in urban settingsupports rural population has higher compliance and urban population has lower compliance at the last MDA 2016 (Table No 11).

Table6. Measures of prevention of Trachoma: respondents' knowledge/view, Magaragadi VDC Bardiya, Kajurakhurda VDC and Nepalgunj Sub-metropolitan City Banke, 2072/2073

\begin{tabular}{|l|l|c|c|}
\hline SN & Preventive measures & Number & Percentage \\
\hline 1 & Face washing & 10 & $7 \%$ \\
\hline 2 & Avoid dust/sun heat/smoke & 10 & $7 \%$ \\
\hline 3 & Take medicine & 4 & $3 \%$ \\
\hline 4 & Keep cleanliness of environment & 6 & $4 \%$ \\
\hline 5 & Eat yellowish fruit and green vegetable & 1 & $1 \%$ \\
\hline
\end{tabular}

Table7. Major source of information of the respondents, Magaragadi VDC Bardiya, Kajurakhurda VDC and NepalgunjSub-metropolitan CityBanke, 2072/2073

\begin{tabular}{|l|l|c|c|}
\hline SN & Source of information & Number & Percentage \\
\hline 1 & Radio & 17 & $12 \%$ \\
\hline 2 & Television & 10 & $7 \%$ \\
\hline 3 & Printed material (leaflet, pamphlet, poster, book etc) & 10 & $7 \%$ \\
\hline 4 & Health Worker & 46 & $33 \%$ \\
\hline 5 & Village leader & 7 & $5 \%$ \\
\hline
\end{tabular}

Table8. Mode of transmission of Lymphatic Filariasis: Respondents' knowledge, Magaragadi VDC Bardiya, Kajurakhurda VDC and NepalgunjSub-metropolitan CityBanke, 2072/2073

\begin{tabular}{|l|l|c|c|}
\hline SN & Mode of transmission & Number & Percentage \\
\hline 1 & From Mosquito bite & 84 & $60 \%$ \\
\hline 2 & Through Respiration & 8 & $6 \%$ \\
\hline 3 & FromHouse fly & 11 & $8 \%$ \\
\hline 4 & From dirty water and food & 27 & $19 \%$ \\
\hline
\end{tabular}

Table9. Compliance of Mass Drug Administration for Lymphatic Filariasis prevention 2016, Magaragadi VDC Bardiya, Kajurakhurda VDC and NepalgunjSub-metropolitan CityBanke, 2072/2073

\begin{tabular}{|l|l|c|c|}
\hline SN & Peoples compliance & Number & Percentage \\
\hline 1 & Respondents interviewed & 139 & $96 \%$ \\
\hline 2 & Respondents aware about MDA 2016 & 133 & $58 \%$ \\
\hline 3 & Respondents took medicine at MDA & 80 & \\
\hline 4 & $\begin{array}{l}\text { Total members age }>2 \text { years at the family of } \\
\text { respondents }\end{array}$ & 530 & $71 \%$ \\
\hline 5 & Family members took medicine at MDA & 27 & $22 \%$ \\
\hline 6 & $\begin{array}{l}\text { Respondents or their family experienced side effect of } \\
\text { the drug taken at MDA }\end{array}$ & 587 & \\
\hline
\end{tabular}


Community Awareness on Neglected Tropical Diseases \& Compliance to Mass Drug Administration against Lymphatic Filariasis in Bardiya and Banke Nepal

Table10. Reasons for not compliance (Not taking medicine at MDA program), Magaragadi VDC Bardiya, Kajurakhurda VDC and NepalgunjSub-metropolitan CityBanke, 2072/2073

\begin{tabular}{|l|l|c|c|}
\hline SN & Reasons & Number & Percentage \\
\hline 1 & Did not know when the medicine was distributed & 3 & $5 \%$ \\
\hline 2 & Out of area during the period of MDA & 13 & $22 \%$ \\
\hline 3 & Fear of side effect of drug & 14 & $24 \%$ \\
\hline 4 & No problem so why to take medicine & 2 & $3 \%$ \\
\hline 5 & $\begin{array}{l}\text { Suffering from other illness and taking other } \\
\text { medicines }\end{array}$ & 26 & $44 \%$ \\
\hline
\end{tabular}

Table11. Compliance to MDA by people residing at rural or urban setting, Magaragadi VDC Bardiya, Kajurakhurda VDC and Nepalgunj Sub-metropolitan City Banke, 2072/2073

\begin{tabular}{|l|l|c|c|c|c|c|}
\hline SN & Residing at setting & $\begin{array}{c}\text { Total } \\
\text { respondents }\end{array}$ & $\begin{array}{c}\text { No of family } \\
\text { members age } \\
>2 \text { years }\end{array}$ & $\begin{array}{c}\text { Family } \\
\text { members } \\
\text { took MDA } \\
\text { medicines }\end{array}$ & $\begin{array}{c}\% \text { of } \\
\text { people } \\
\text { took } \\
\text { MDA }\end{array}$ & OR* \\
\hline 1 & Magaragadi VDC (Rural) & 61 & 345 & 266 & $77 \%$ & 2.46 \\
\hline 2 & Khajurakhurda VDC (Rural) & 24 & 164 & 126 & $77 \%$ & 2.42 \\
\hline 3 & NepalgunjSub-metropolitan City & 27 & 142 & 82 & $58 \%$ & 0.4 \\
\hline 4 & $\begin{array}{l}\text { Mixed residence (people visiting } \\
\text { at clinic) }\end{array}$ & 27 & 162 & 113 & $70 \%$ & $\begin{array}{c}\text { Not } \\
\text { calculate }\end{array}$ \\
\hline
\end{tabular}

\section{DISCUSSION}

Our study confirms that community people have very less knowledge about neglected tropical diseases prevailing at Nepal. Compared to other NTDs more people have heard about Lymphatic Filariasis and 60\% people know it transmits from mosquito bite. Regarding the preventive measures, peoples' knowledge is very less in any NTDs. Our study showed only $71 \%$ people among total members at families took medicine during the last MDA 2016. The reason for not taking medicine mostly said was suffering from other illness and taking treatment for that $(44 \%)$ or fear of side effect of the drugs (24\%). The compliance to MDA of rural people is higher than that of the urban population which shows people of urban setting are more negligent to the disease "Filariasis" or don't give importance to MDA or activities to cover mass population at urban area is not sufficient. Although better than the urban population, the compliance to MDA of rural population is also less than the target given byWHO which is $65 \%$ among total and $80 \%$ among eligible population.(World Health Organization, 2010)

In conclusion, peoples' knowledge on Lymphatic Filariasis as well as other NTDs is very less. Peoples' compliance to MDA campaign is less. Urgent attention and action is required to take to eliminate Lymphatic Filariasis from Nepal by year 2020 .

\section{RECOMMENDATION}

Following actions could be helpful to fulfill the gaps seen in the area of NTD.

1. Continuous awareness raising at community and accelerated even more at the time of annual campaign of MDA.

2. Increased activities at urban areas to increase access and coverage of urban population.

3. Nepal Government could not do everything to eliminate NTDs from the country. Joining hands of supporting partner is necessary.

Further study will be helpful for more information on situation. 
Community Awareness on Neglected Tropical Diseases \& Compliance to Mass Drug Administration against Lymphatic Filariasis in Bardiya and Banke Nepal

\section{Acknowledgement}

The authors are thankful to all enumerators Ms. PhulbasniChaudhari, Ms. Kalpana Chaudhari, Ms. Ganga Chaudhari, Mr. Anil BK, Mr. Pabitra BM, Ms.Shanti Rawal, Ms. Nirmala BM and Ms. Jaisara Budha for their support of data collection and all the respondents who cooperated with us and provided valuable information. Sincere thanks also go to Mr. Tilak Gharti for data entry in designed format and Mr. Yam KC for his safe driving during the field visits.

\section{REFERENCES}

Geography of Nepal. (n.d.). Retrieved 3 29, 2016, from http://web.gps.caltech.edu/ avouac/nepal_trip/ geography.htm

Government of Nepal, M. o. (2070-2071 (2013-2014)). Annual Report 2013-2014. Kathmandu: Nepal Government.

MOHP, H. S. (2072). Lymphatic Filariasis Elimination Programm, Training and Programme Iimplementation Manual for Health Workers. Kathmandu.

SANGH, N. N. (2014). Annual Report-National Trachoma Programme. Kathmandu: NEPAL NETRA JYOTI SANGH.

World Health Organization, R. O. (2010). The Regional Strategic Plan for Elimination of Lymphatic Filariasissis 2010-2015. New Delhi: World Health Organization, Regional Office for South East Asia,World Health House New Delhi India.

Citation: Mangal Bahadur Tharu, Surya Kumar Magar, Rajendra Bahadur Sunar, “Community Awareness on Neglected Tropical Diseases \& Compliance to Mass Drug Administration against Lymphatic Filariasis in Bardiya and Banke Nepal". American Research Journal of Public Health; 1(1): 43-49.

Copyright () Mangal Bahadur Tharu, Surya Kumar Magar, Rajendra Bahadur Sunar, This is an open access article distributed under the Creative Commons Attribution License, which permits unrestricted use, distribution, and reproduction in any medium, provided the original work is properly cited. 